\title{
Knowledge, Attitude and Practice of Saudi Parents Towards Their Children's Oral Health: An Online Questionnaire Survey
}

\author{
Malaz Mohamed Elrafie Mustafa, Ebtehaj Saleh Albeshri, and Mashael Khaled Althobati
}

\begin{abstract}
Children's oral health is of paramount importance as it governs the oral health status of the upcoming generation. Their oral hygiene is a vital part of general childcare. This under-appraised issue is often neglected by young parents, which can result in poor children's oral health. Aim: To assess standard knowledge, attitude and behavior of Saudi parents pertaining to the oral health of their young children. Materials and Methods: a prospective cross-sectional online survey was conducted in Saudi Arabia in 2017. The questionnaire included a total of $\mathbf{1 6}$ questions which were divided into two parts; the first part asked about parents' general information such as the name, age, gender, educational level, occupation and total family income. The second part included questions related to knowledge, attitude and practices toward children on selected oral health issues. Results: 1038 Saudi parents responded to the online questionnaire $(70 \%$ Females and $30 \%$ male). Majority Saudi parents recognized many preventive dental aspects like importance of early acquisition of tooth brushing, avoidance of caries-related diet and nocturnal on demand breast feeding. Seventy three percent were convinced that it is better to take their children to a specialized pediatric dentist rather than a general dental practitioner. However, it was revealed that there was limited knowledge and awareness of Saudi parents about the significance of the routine dental checkups, ideal timing of first dental visit and importance of topical fluoride. Hypothetical myths and social beliefs associated with dental treatment like endodontic treatment were common; creating barriers to early preventive and curative dental care of young Saudi children. Conclusion: Parents were found to have inadequate knowledge in regard to oral health of their young children. The present research points to a need for enhanced dental education of parents, particularly in planning for their children's first visit and effect of prolonged on-demand at night breast feeding on development of early childhood caries. Community based oral health programs are required in order to raise parents' awareness regarding their children's oral health.
\end{abstract}

Index Terms-Attitude, Knowledge, Oral health, Parents.

\section{INTRODUCTION}

Children's oral health is of paramount importance as it governs the oral health status of the upcoming generation. Their oral hygiene is a vital part of general childcare. This under-appraised issue is often neglected by young parents, which can result in poor children's oral health [1].

Influencing the oral health status of children requires motivating the parent/guardian to gain a better understanding of the factors affecting the child's oral health [2].

Published on September 25, 2019
Early childhood caries (ECC) is deemed to be an infectious transmissible disease influenced by behavioral and social factors, with community centered preventive measures considered as a cornerstone in its prevention [3].

Parents and guardians are role models for their children in all aspects of life including health attitude and practices, their role in raising their children's awareness towards the importance of oral health practices is crucial [4].

Researches demonstrate that negative parental attitudes towards their children's oral health and limited perceived control are risk indicators for caries experience in their offspring $[5,6]$.

Children acquiring poor oral health habits are at a higher risk to experience dental caries as compared to those who have positive habits [7-9].

It has been advocated that early childhood caries (ECC) should be considered as

a communicable disease related to behavioral and social influences, with public preventive measures being recommended [3]

As parents are the primary caretakers of their children, they should have knowledge about dental health of primary teeth, its maintenance so as to build confidence in their children [10].

Little is known about the oral health attitudes and behavior of Saudi parents towards their children's oral health. This study provides baseline data for forthcoming researches.

Hence, an attempt has been made in the current survey to assess standard knowledge, attitude and behavior of parents pertaining to the oral health of their young children.

\section{MATERIALS AND METHODS}

\section{A. Study design}

This was a prospective cross-sectional survey conducted in Saudi Arabia in 2017.

\section{B. Study population}

All Saudi parents having children aged below 5-year-old were asked to participate on the online survey

\section{Method of data collection}

A structured online questionnaire was set and uploaded after checking its reliability and validity.

The questionnaire was designed originally in English and then translated to Arabic. The Arabic version was then back-translated into English and compared to the original English version to check for translation accuracy. 
The questionnaire included a total of 16 questions which were divided into two parts. The first part asked about parents' general information such as the name, age, gender, educational level, occupation and total family income. The second part included questions related to knowledge, attitude and practices toward children on selected oral health issues.

\section{Ethical considerations}

Ethical clearance was obtained from Scientific Research Committee of king Khalid University, College of Dentistry.

\section{RESULTS}

1038 Saudi parents responded to the online questionnaire (70\% Females and 30\% male). More than half of the respondents were unemployed but having college or university degrees $(58 \%)$.

Most of Saudi parents agreed to take their children to specialized pediatric dentist (73\%) and 79\% consider primary teeth as important.

Forty six percent knew that only a pediatric dentist is trained in the field of child psychology and behavior management while 55\% didn't know about it.

When parents were asked about the option of endodontic treatment for their children's primary teeth, half of them considered it as not possible (Figure 1.).

Sixty nine percent of Saudi parents acknowledged that infection from a decayed milk tooth can affect the unerupted permanent successor, whereas $14 \%$ were convinced that primary teeth infection cannot be transmitted to the succedaneous tooth, while $17 \%$ didn't have any idea about it.

Half of the participants (50\%) acknowledged the importance of topical fluoride for milk teeth $55 \%$ of whom believe it has a caries-protective effect, whereas $42 \%$ recognized it increases tooth resistance against caries attack and rest stated it has a potent anti- bacterial property. Yet the other half believed that topical fluoride application is of minor significance.

Most of Saudi parents considered going to dentist is of prime importance only if their child suffers from tooth decay or dental pain (Figure 2).

More than one-half of respondents (59\%) believed that ideal timing for their children first dental visit should be related to the presence of dental pain (Figure 3).

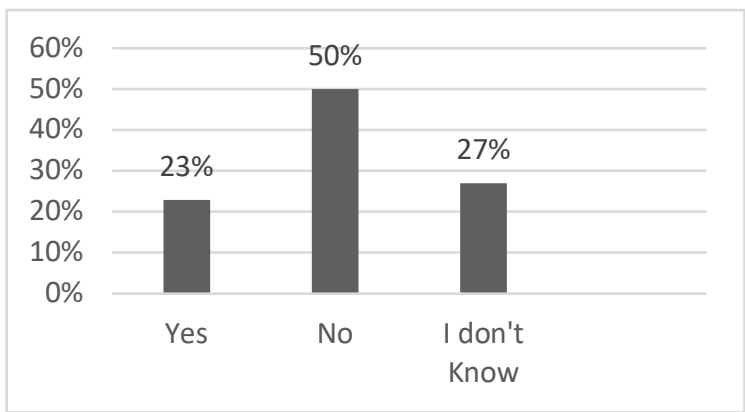

Fig. 1. Saudi parents' response to the question: Can milk teeth be treated using root canal treatment procedure?

Brushing should be started as early as first deciduous tooth eruption; this fact was acknowledged by $75 \%$ of respondents, while $22 \%$ believed brushing should be practiced after eruption of permanent teeth. Two percent of Saudi parents believed brushing is of trivial importance while $1 \%$ didn't know the ideal timing to start brushing.

Majority of respondents recognized that consuming refined carbohydrates and sugary diet can result in tooth decay $(90 \%)$.

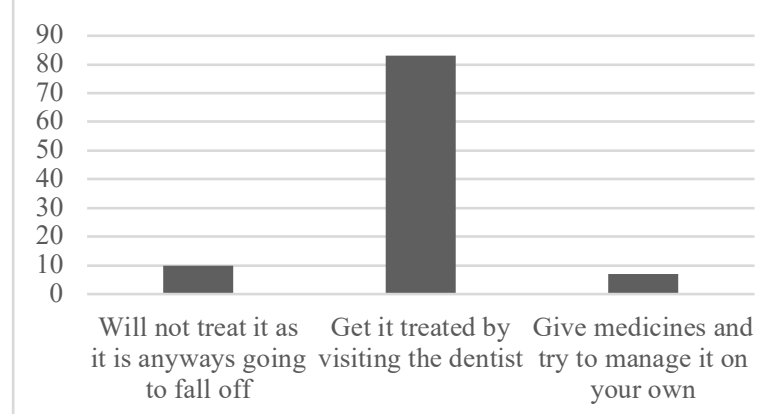

Fig. 2. Saudi parents' response to the question: what would you do if your child's teeth are decayed?

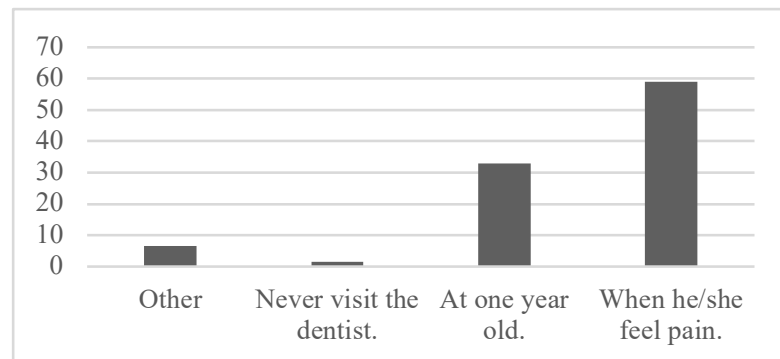

Fig. 3. Parental knowledge about ideal timing for the first dental visit.

Forty percent of Saudi parents assumed that prolonged, on demand breast feeding do not contribute to early childhood caries, however, $34 \%$ believed breast feeding can cause caries in children, the remaining $26 \%$ were not aware of this fact.

\section{Discussion}

A profound estimation of parental knowledge, attitudes, views and awareness concerning oral health is vital for proper implication of oral health promotion strategies intended for improving the dental health of young children.

Children below 5 years of age are supposed to be in close contact with their parents or guardians, this connection continues even after joining nurseries and preschool classes. These early childhood years comprise "primary socialization" where the basic childhood practices and behaviors are learned [11].

The questionnaires principally emphasized on the awareness of parents about oral health of their children, its related risk and protective aspects that are expected to have an impact on their children's dental behavior and practices. Moreover, we studied the influence of socio-demographic factors on parental knowledge, attitude and practices.

Dentists and specifically pediatric dentists can play a prime part in abolishing the fear of parents and children by applying professional behavior management methods, retraining the parental undesirable behaviors as a result of poor past experiences and instructing parents about the preventive dental measures that reduce distress and pain [12]. In this study, only $46 \%$ of participants were aware of the fact that only a pediatric dentist is trained in the field of child psychology and behavior management while more 
than one-half didn't know about it.

One-half of respondents refused the idea of endodontically treating primary teeth; this result was partially due to the many myths linked to root canal treatment like vision loss and carcinogenic effect of the procedure. Similar results were reported in other studies [12]. An in-depth knowledge about these cultural views could help the dentist to better explain the merits of dental treatments [13].

Fluoride has a defensive role against the initiation of tooth decay [14]. In this study, knowledge regarding role of fluoride was average with half respondents acknowledging its importance in preventing dental caries. Findings in the literature were variable; some reported poor knowledge as studies conducted by Moulana et al [15] and Suresh et al. [16]. On the other hand, some reflected high level of awareness among participants $[17,18]$.

The results of this study were in accordance to the outcomes of studies done by Moulana et al.,[15] Wyne et al.,[19] Kamolmatyakul and Saiong [20] and Chan et al. [21] where majority of the Saudi parents were found to be aware that sweetened diet like chocolates can lead to dental decay.

Majority of the Saudi parents (81\%) conceptualized the necessity to take their children for dental only in case of tooth decay, to receive the appropriate dental treatment, which was similar to the results of Moulana et al. [15] and Chan et al. [21].

Only $32.9 \%$ of participants were in opinion that first dental visit should ideally be by the child' first birthday, whereas more than half of them are convinced that child should visit the dentist whenever there is a need. This opinion does not come in accordance with the recommendation that the earlier a child visits a dentist, the lesser would be his risk of developing dental caries [22].

The mainstream of respondents was in line with the importance of primary teeth (83\%), this result contradict the finding of Suresh et al. [16] in which poor knowledge of the importance of primary teeth was reported.

More than one-half of Saudi parents in the current study were convinced that first dental visit should take place whenever their child suffers from dental pain or decay. Whereas only $32.9 \%$ believed it should ideally take place at one-year-old. Similar results were reported by AlShalan, 2003 [23] where Saudi parents supposed that dental checkup before the child's first birthday was untimely, with the majority preferring the age range of 3-6 years for the first dental visit.

In the present study, majority of Saudi parents recognized the importance of starting tooth brushing as early as the first primary tooth erupt $(75 \%)$. Similar results were found in rural Australia where majority of parents believed that they should start brushing when the first tooth erupts [17]. Contrary to our findings, a study conducted in Mumbai revealed that most mothers believed that tooth brushing for their child should only be practiced following eruption of all primary teeth of their children [24].

Sixty-nine percent of Saudi parents were aware of the fact that primary tooth decay can infect the permanent succors. Similar results were reported by Chhabra, N. et al. in 2012 [12] where only $46 \%$ of addressed parents believed there was no link between caries affecting the primary predecessor and subsequent infection of permanent successor, whereas the remaining $54 \%$ were in opinion with this fact.

\section{CONCLUSION}

The present study revealed that respondent parents had superficial or partial knowledge and awareness about primary teeth, its importance and maintenance. This level of knowledge is insufficient to maintain the oral health of the offspring and requires constant developing.

There is a need to cultivate and reinforce positive attitude among parents and substantially raise their dental awareness through child dental health-oriented programs with active parental involvement. Such awareness programs should be developed for parents imparting knowledge about primary teeth, their function and preventive primary care of these teeth. To achieve this, young and prospective parents should be directed by the medical professionals, obstetricians, gynecologists and pediatricians to seek professional oral health counseling.

\section{ACKNOWLEDGEMENT}

We would like to express our gratitude to Scientific research committee of King Khalid University for reviewing this manuscript. Our gratefulness goes to Saudi parents whotook part in this study.

\section{REFERENCES}

[1] Wapniarska, K., K. Bula, and A. Hilt, Parent's pro-health awareness concerning oral health of their children in the light of survey research. Przegl Epidemiol, 2016. 70(1): p. 59-63, 137-40.

[2] Weatherwax, J.A., et al., Exploration of the relationship between parent/guardian sociodemographics, intention, and knowledge and the oral health status of their children/wards enrolled in a Central Florida Head Start Program. Int J Dent Hyg, 2015. 13(1): p. 49-55.

[3] Weinstein, P., Public health issues in early childhood caries. Community Dent Oral Epidemiol, 1998. 26(1 Suppl): p. 84-90.

[4] Shivaprakash, P.K., et al., The state of infant oral healthcare knowledge and awareness: disparity among parents and healthcare professionals. J Indian Soc Pedod Prev Dent, 2009. 27(1): p. 39-43.

[5] Finlayson, T.L., et al., Psychosocial factors and early childhood caries among low-income African-American children in Detroit. Community Dent Oral Epidemiol, 2007. 35(6): p. 439-48.

[6] Schroth, R.J., D.J. Brothwell, and M.E. Moffatt, Caregiver knowledge and attitudes of preschool oral health and early childhood caries (ECC). Int J Circumpolar Health, 2007. 66(2): p. 153-67.

[7] Mattila, M., et al., Behavioural and demographic factors during early childhood and poor dental health at 10 years of age. Caries Res, 2005. 39: p. 85-91.

[8] Hausen, H., S. Kärkkäinen, and L. Seppä, Application of the highrisk strategy to control dental caries. Community Dent Oral Epidemiol, 2000. 28: p. 26-34.

[9] Gibson, S. and S. Williams, Dental caries in pre-school children: associations with social class, toothbrushing habit and consumption of sugars and sugar-containing foods. Further analysis of data from the National Diet and Nutrition Survey of children aged 1.5-4.5 years. Caries Res, 1999. 33: p. 101-13.

[10] Akpabio, A., C.P. Klausner, and M.R. Inglehart, Mothers'/guardians' knowledge about promoting children's oral health. J Dent Hyg, 2008. 82(1): p. 12.

[11] Holm, A., Caries in pre-school children: international trends. J Dent, 1990: p. 291-5.

[12] Chhabra, N. and A. Chhabra, Parental knowledge, attitudes and cultural beliefs regarding oral health and dental care of preschool children in an Indian population: a quantitative study. Eur Arch Paediatr Dent, 2012. 13(2): p. 76-82.

[13] Wong, D., S. Perez-Spiess, and K. Julliard, Attitudes of Chinese parents toward the oral health of their children with caries: a qualitative study. Pediatr Dent, 2005. 27(6): p. 505-12. 
[14] Davies, G.M., et al., A randomised controlled trial of the effectiveness of providing free fluoride toothpaste from the age of 12 months on reducing caries in 5-6-year-old children. Community Dent Health, 2002. 19(3): p. 131-6.

[15] Moulana. SA, et al., Knowledge, attitude and practices towards primary dentition among the mothers of 3-5-year-old pre-school children in Bangalore city. J Indian Assoc Public Health Dent 2012. 19: p. 83-92.

[16] Suresh, B.S., et al., Mother's knowledge about pre-school child's oral health. J Indian Soc Pedod Prev Dent, 2010. 28(4): p. 282-7.

[17] Gussy, M.G., et al., Parental knowledge, beliefs and behaviours for oral health of toddlers residing in rural Victoria. Aust Dent J, 2008. 53(1): p. 52-60.

[18] Franzman, M.R., et al., Tooth-brushing and dentifrice use among children ages 6 to 60 months. Pediatr Dent, 2004. 26(1): p. 87-92.

[19] Wyne, A.H., et al., Oral health knowledge and sources of information among male Saudi school children. Odontostomatol Trop, 2004. 27(106): p. 22-6.

[20] Kamolmatyakul. S and S. S., Oral health knowledge, attitude and practices of parents attending Prince of Songkla University Dental Hospital. Int J Health Promot Educ, 2007. 45: p. 111-3.

[21] Chan, S.C., J.S. Tsai, and N.M. King, Feeding and oral hygiene habits of preschool children in Hong Kong and their caregivers' dental knowledge and attitudes. Int J Paediatr Dent, 2002. 12(5): p. 322-31.

[22] Al Ghanim, N.A., et al., Caries prediction model in pre-school children in Riyadh, Saudi Arabia. Int J Paediatr Dent, 1998. 8(2): p. 115-22.

[23] Al-Shalan, T.A., Factors affecting Saudi parents' perception of their children's first dental visit. J Contemp Dent Pract, 2003. 4(4): p. 5466.

[24] Jain, R., K. Oswal, and R. Chitguppi, Knowledge, attitude and practices of mothers toward their children's oral health: A questionnaire survey among subpopulation in Mumbai (India). Journal of Journal of Dental Research and Scientific Development, 2014. 1: p. 40.

\section{AUTHORS INFORMATION}

Malaz Mohamed Elrafie Mustafa, born in Khartoum (Sudan), Graduated from faculty of Dentistry, University of Khartoum (Sudan) (BDS 2003). Obtained Master of Science in Pediatric Dentistry (MSc) from University of Khartoum in 2011. In 2013, become a member of Faculty of DentistryRoyal College of Surgeons in Ireland (MFD-RCSI). Became a member of the Royal College of Physician and Surgeons- Glasgow (MRCPS-Glasgow in 2017).

Award Of MFD-RCSI for best academic performance in 2013.

Currently Lecturer of Pediatric Dentistry at College of Dentistry, King Khalid University.

Ebtehaj Saleh Albeshri, born in Saudi Arabia, Graduated from College of Dentistry, King Khalid University.

Currently, general dental practitioner in a private clinic.

Mashael Khaled Althobati, born in Saudi Arabia, Graduated from College of Dentistry, King Khalid University.

Currently, general dental practitioner in a private clinic. 